\title{
The canine isolate Lactobacillus acidophilus LAB20 adheres to intestinal epithelium and attenuates LPS-induced IL-8 secretion of enterocytes in vitro
}

\author{
Veera Kainulainen ${ }^{1 *}$, Yurui Tang ${ }^{2}$, Thomas Spillmann ${ }^{3}$, Susanne Kilpinen ${ }^{3}$, Justus Reunanen ${ }^{1}$, Per EJ Saris ${ }^{2}$ \\ and Reetta Satokari ${ }^{1}$
}

\begin{abstract}
Background: For a good probiotic candidate, the abilities to adhere to intestinal epithelium and to fortify barrier function are considered to be crucial for colonization and functionality of the strain. The strain Lactobacillus acidophilus LAB20 was isolated from the jejunum of a healthy dog, where it was found to be the most pre-dominant lactobacilli. In this study, the adhesion ability of LAB20 to intestinal epithelial cell (IECs) lines, IECs isolated from canine intestinal biopsies, and to canine, porcine and human intestinal mucus was investigated. Further, we studied the ability of LAB20 to fortify the epithelial cell monolayer and to reduce LPS-induced interleukin (IL-8) release from enterocytes.

Results: We found that LAB20 presented higher adhesion to canine colonic mucus as compared to mucus isolated from porcine colon. LAB20 showed adhesion to HT-29 and Caco-2 cell lines, and importantly also to canine IECs isolated from canine intestinal biopsies. In addition, LAB20 increased the transepithelial electrical resistance (TER) of enterocyte monolayers and thus strengthened the intestinal barrier function. The strain showed also anti-inflammatory capacity in being able to attenuate the LPS-induced IL-8 production of HT-29 cells.
\end{abstract}

Conclusion: In conclusion, canine indigenous strain LAB20 is a potential probiotic candidate for dogs adhering to the host epithelium and showing intestinal barrier fortifying and anti-inflammatory effects.

Keywords: Lactobacillus, Probiotics, Adhesion, Anti-inflammatory, Transepithelial resistance, Interleukin-8, Canine

\section{Background}

The mammalian gastrointestinal tract (GIT) is colonized by a complex microbiota, which interacts with the host mucosa and maintains mucosal homeostasis in healthy individuals $[1,2]$. Studies on mice model have shown that the initial development of immune system is profoundly influenced by the colonization of gut microbiota [3]. The deficiency of immune maturation and the development of intolerance towards commensal bacteria may lead to chronic inflammatory diseases later in life $[1,3]$. The maintenance of intestinal immune and physiological homeostasis in mammals is mediated by sophisticated interaction between intestinal microbiota and the host mucosa, which consists of the epithelial cell layer and

\footnotetext{
* Correspondence: veera.kainulainen@helsinki.fi

'Department of Veterinary Biosciences, Faculty of Veterinary Medicine, University of Helsinki, P.O. Box 66 (Agnes Sjöberginkatu 2)Fl-00014 Helsinki, Finland

Full list of author information is available at the end of the article
}

underlying lamina propria. The epithelial cell layer is not merely a physical barrier, but also responds to stimuli, e.g. by secreting mucus and inducing innate and adaptive immune responses $[4,5]$. Intestinal epithelial cells (IECs) express several pattern recognition receptors (PRRs) and can detect microorganism-associated molecular patterns (MAMPs) and subsequently release effector cytokines. Thus, IECs are important players in orchestrating tolerance or inflammatory responses against the resident microbiota. Commensal microbes have often developed a mutualistic relationship with the host and induce tolerogenic or immunoregulatory responses in the host [4].

Adhesion is considered as a crucial step for intestinal bacteria to colonize and further interact with the host epithelium and immune system. Intestinal bacteria can adhere to mucus, or bind to exposed IECs via their surface structures [6-9]. Lactobacillus species can be found along the mammalian GIT with various counts, typically 
being more dominant in the proximal small intestine [10]. The majority of strains utilized as probiotics belong to the genus Lactobacillus and a number of strains have been shown to adhere strongly to the epithelium [11-15]. Probiotics have been shown to modulate immune responses, being able to competitively exclude pathogenic bacteria, and enhance epithelial barrier functions [4]. Promising results have been obtained also in alleviating gastrointestinal disorders [16].

In response to enteropathogen infection, the intestinal epithelium releases proinflammatory molecules to recruit immune cells and induce an acute inflammatory response. Inflammation is an essential physiological response to infection and tissue protection, but nonregulated inflammatory responses can give rise to tissue injury and chronic disease $[1,16]$. Interleukin- 8 (IL-8) is one of the key chemokines, which is responsible for the initiation of inflammatory cascades and recruitment of neutrophils into the mucosa [17]. It is considered, that after the acute inflammation, commensal bacteria have a key role in providing regulatory immune stimuli to extinguish the inflammation back to basal level [1]. Also probiotics have been demonstrated to suppress mucosal inflammation and restore cytokine balance towards an anti-inflammatory state [18-22].

Lactobacillus acidophilus strain LAB20 was isolated from canine small intestine, where it was found to be among predominant jejunal lactobacilli [23]. Further, administered LAB20 could persist in the dog gut for more than six weeks post-administration [24], which is a remarkably long period for a probiotic strain. Typically, probiotics are cleared from the majority of patients within weeks after the administration is terminated $[25,26]$. In the present study, we investigated the interaction of LAB20 with the host epithelium. We studied it's adhesion ability to canine mucus and IECs from different compartment of dog intestine and to IEC lines. Further, we assessed the ability of LAB20 to attenuate LPS-induced IL-8 release from IECs and to fortify epithelial barrier function.

\section{Results}

\section{Adhesion to mucus}

First, we studied the ability of $L$. acidophilus LAB20 to bind mucus isolated from duodenum, jejunum, ileum, cecum and colon of canine intestine. We found that LAB20 showed very similar adhesion efficiency to canine mucus despite the mucus type i.e. from which intestinal compartments the mucus was isolated from (Figure 1A). Next, the capacity of LAB20 to adhere canine, human and porcine colonic mucus was compared. Human derived strain Lactobacillus rhamnosus GG (LGG), which has previously been shown to bind to human colonic mucus $[7,27]$ was included in the experiment for comparison. LAB20 presented statistically significantly higher adhesion to canine colonic mucus (1.6\%) compared to adhesion to porcine $(0.7 \%)$ mucus $(\mathrm{p}<0.05$, Figure $1 \mathrm{~B})$. However, the binding of LAB20 to human (1.0\%) mucus was not significantly different from adhesion to canine mucus. LGG adhered to human (3.8\%) and porcine $(2.2 \%)$ mucus more efficiently than LAB20 $(\mathrm{p}<0.05)$, whereas LAB20 showed higher adhesion to canine mucus (Figure 1B).

\section{Adhesion to IECs}

Next, we studied the adherence of LAB20 to the epithelial cell lines of different ages. Caco-2 cells differentiate in 14 days after confluence [28], and the adhesion was examined with undifferentiated cells (3 days) in addition to cells at two differentiation stages ( 8 and 21 days). For

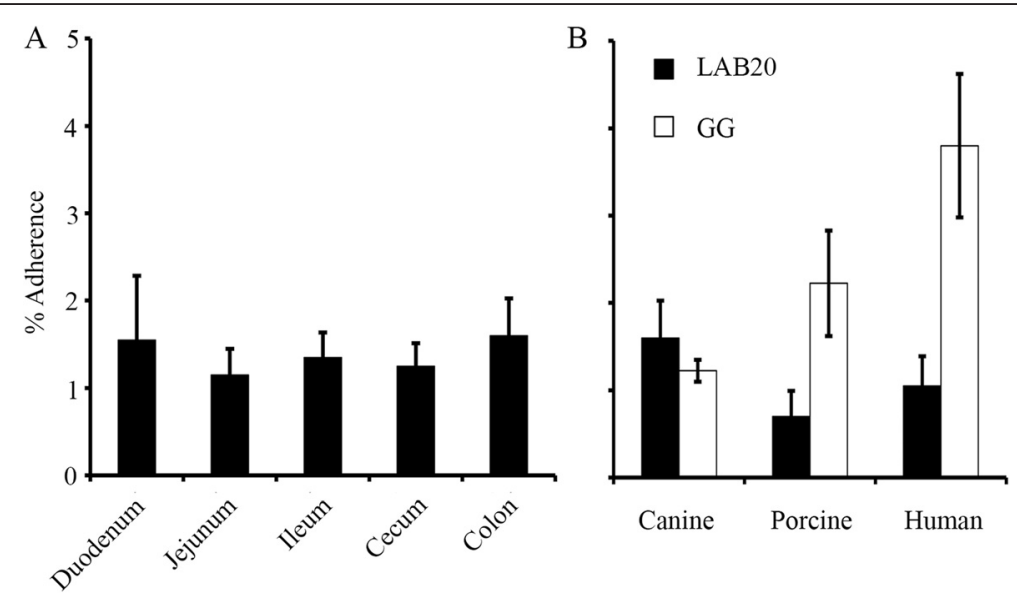

Figure 1 Adhesion of $\mathbf{L}$. acidophilus LAB20 to mucus. Adhesion (\%) of ${ }^{3} \mathrm{H}$-labeled LAB20 to mucus isolated from canine duodenum, jejunum, ileum, cecum, and colon (A) and to colonic mucus from different hosts (B) was measured. The human derived strain ${ }^{3} \mathrm{H}$-labeled $\mathrm{L}$. rhamnosus $\mathrm{GG}$ was included for comparison. Results are the means \pm standard deviations of five technical replicates (parallel wells) of the representative experiments. 
comparison, the same growth times were used for HT29 cell line. LAB20 adhered similarly to Caco-2 and HT29 cell lines and there was no statistically significant difference in the adherence of LAB20 to IECs of different ages except the adhesion to 3-days old Caco-2 cells was significantly lower compared to 8-days old but not to 21-days old Caco-2 cells (Figure 2). In order to examine the adhesion of LAB20 to canine IECs, FITC-labeled LAB20 cells were visualized with epifluorescence microscopy. LAB20 adhered to canine IECs isolated from various parts of the intestine (Figure 3). The adherence to IECS isolated from cecum and colon seemed higher than to IECs from duodenum, jejunum or ileum, but the assay did not allow proper quantitative measurement and therefore, this difference remains unconfirmed.

\section{Ability to attenuate LPS-induced IL-8 production of enterocytes}

In order to assess the potential anti-inflammatory properties of LAB20, we measured its ability to reduce the LPS-induced release of IL- 8 from the HT-29 cell line. The attenuation effect on IL-8 production was evaluated by incubating HT-29 monolayer with LPS (0.1 or $1 \mathrm{ng} / \mathrm{ml}$ ) after the cell line was first exposed to fresh and freezedried LAB20 and sterile culture medium (Figure 4). Prior co-incubation of HT-29 cells with fresh LAB20 decreased significantly $(\mathrm{P}<0.05)$ the LPS-stimulated IL-8 production with both LPS concentrations. However, the freezedried LAB20 did not show reduction of secreted IL-8 as compared to the freshly cultured LAB20 cells. Taken together, the results showed that the decrease of IL- 8 production, obtained by incubation with LAB20, was depended on the properties of active, living cells. LAB20 recovery from the freeze-dried stage takes more than 8

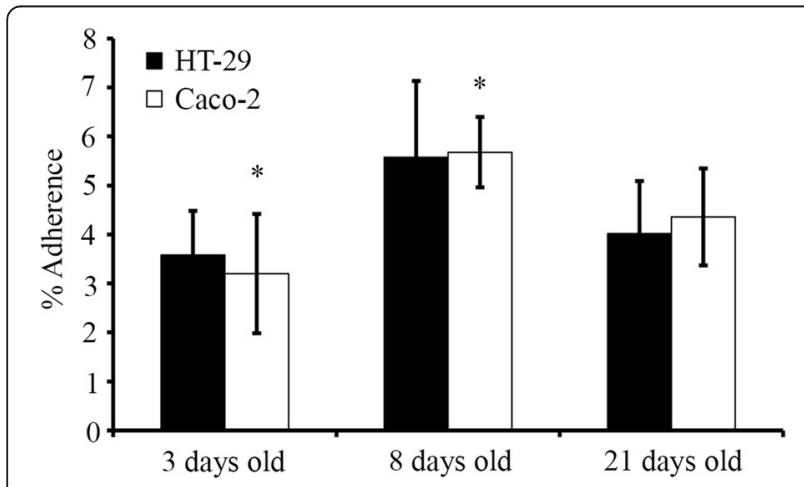

Figure 2 Adhesion of LAB20 to epithelial cell lines. Adhesion (\%) of ${ }^{3} \mathrm{H}$-labeled L. acidophilus LAB30 to 3-, 8-, and 21-day-old Caco-2 and HT-29 cells was measured. The results of five technical replicates (parallel wells) from the representative experiment are expressed as means \pm standard deviations. Significant reduction $(p<0.05)$ in adhesion compared to different aged IECS is indicated with an asterix.
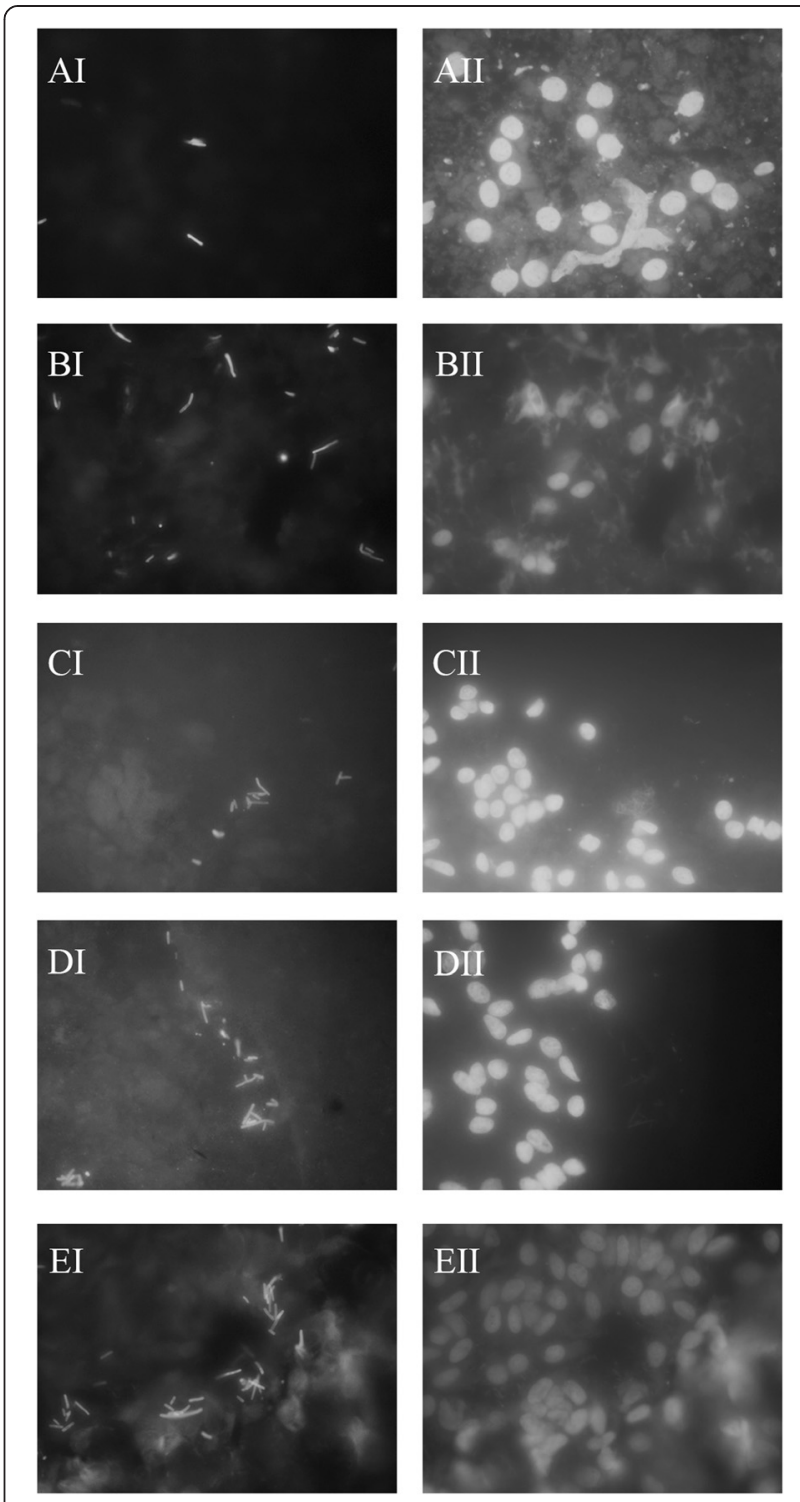

Figure 3 Adhesion of LAB20 to the canine IECs. Adherence of FITC-labelled bacteria to canine IECs obtained from duodenum (A), jejunum (B), ileum (C), cecum (D), and colon (E) sections is shown in the left panel. The arrows indicate LAB20 cells adhered to IECs. The nucleus of IECs were stained with DAPI and are shown in the right column.

hours and thus we presumed it to remain inactive during the one hour incubation of attenuation experiment.

In order to disclose the molecular mechanisms behind the anti-inflammatory action of LAB20 we constructed a recombinant derivate strain, SAA658, to down-regulate the transcription of the exopolysaccharide synthesis epsE gene in LAB20 using antisense RNA strategy (Additional file 1). This strategy was chosen because knock-out mutants were not possible to construct due to the low transformation frequency (approximately 10 transformants $\mu g^{-1}$ DNA) of LAB20. Our preliminary results 


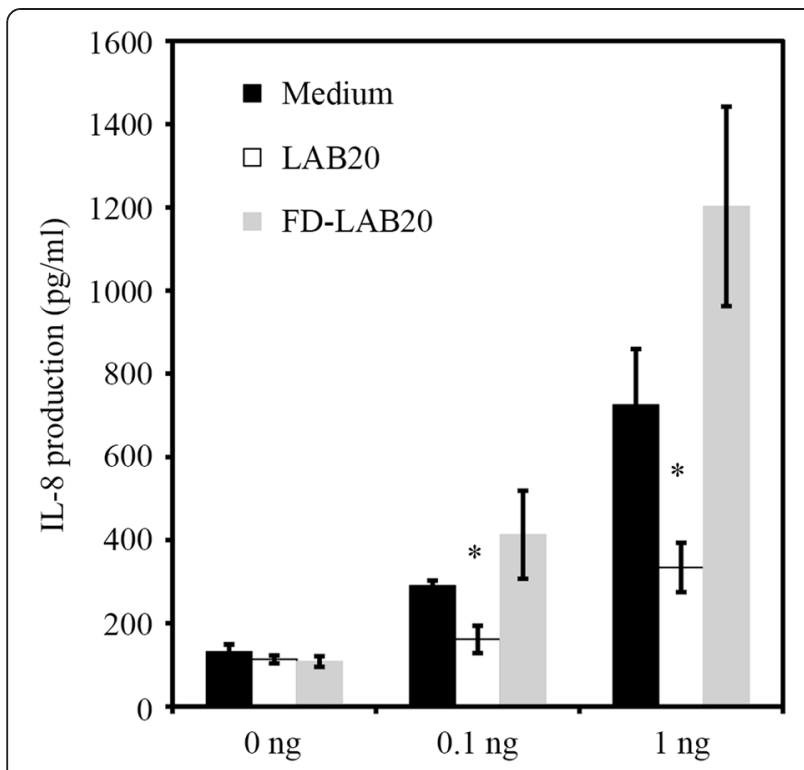

Figure 4 The LPS-induced IL-8 production in HT-29 cells in response to medium, LAB20 cells, and freeze-dried LAB20 (FD-LAB20). Data are expressed as means \pm standard deviations of three technical replicates from a representative experiment. Significant difference $(p<0.05)$ in the IL-8 production as compared to the medium control is indicated with an asterisk.

suggest that exopolysaccharide (EPS) of LAB20 may have a role in the immunomodulatory activity of LAB20 (Additional file 1). However, the detailed properties of the derivate strain and the effector molecules of antiinflammatory action still need to be resolved.

\section{Effects of LAB20 on epithelial barrier function}

The effect of LAB20 on epithelial barrier function was studied by measuring transepithelial electric resistance (TER). Nonpathogenic Escherichia coli has been shown to disrupt the Caco-2 monolayer [29] and we included E. coli TOP10 in the experiment as a negative control. The epithelial cells were incubated with LAB20, E. coli or sterile culture medium for 72 hours and TER was measured every 24 hours. TER of epithelial cells treated with LAB20 was significantly higher as compared to cells treated with culture medium (Figure 5). In contrast, $E$. coli decreased TER significantly already within 24 hours.

\section{Discussion}

Host-microbial interactions in the GIT are important for gut health, first by inducing the maturation of gut immune system in early life, and later in maintaining immune and physiological homeostasis of the mucosa [2,30-32]. It is considered that for an effective interaction with the host mucosa, bacteria must adhere to intestinal mucus or IECs. Adherence of probiotic bacteria to the intestinal epithelium is an important characteristic as it also promotes persistence time and colonization.

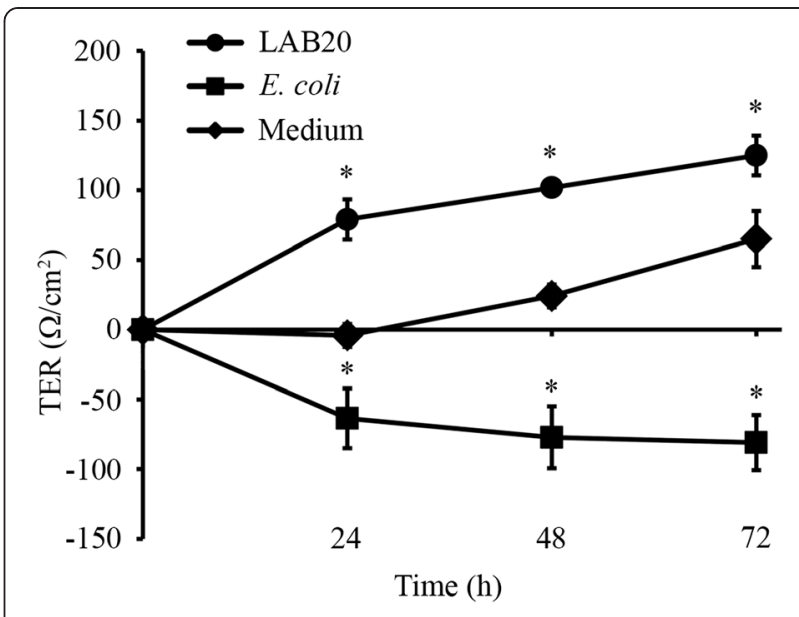

Figure 5 The effect of LAB20 on transepithelial resistance (TER) of the Caco- 2 cell line. TER values $(\Omega / \mathrm{cm} 2)$ are the means \pm standard deviations of three technical replicates from a representative experiment. Significant differences $(p<0.05)$ in TER-values between bacterium-treated and untreated Caco-2 cells are indicated with an asterix.

L. acidophilus LAB20 showed approximately 1.2-1.6\% adhesion to canine mucus isolated from different intestinal compartments (Figure 1A) whereas the adhesion was lower to human- or porcine-derived mucus (Figure 1B). Instead, human-derived strain $L$. rhamnosus GG showed overall the highest adhesion ability to human colonic mucus. The results reinforce the suggestion that the adhesion of bacteria toward mucus is strain-specific, which may be due to the various bacterial surface structures associate with adhesion $[7,11,27,33,34]$. On the other hand, strains may display some degree of host specificity in the adhesion, although the strain origin is not always reflected in host specificity in adhesion $[33,35]$.

The result showed that LAB20 could adhere to both Caco-2 and HT-29 cell lines, which are commonly used in vitro models to study microbe-IEC interactions [36]. Further, with access to canine IECs from different intestinal compartments, we presented that LAB20 could adhere to canine IECs as well. Canine intestinal epithelial cell lines are not commercially available and therefore, we used IECs isolated from duodenum, jejunum, ileum, cecum, and colon biopsies of healthy dogs. The gastrointestinal epithelium is covered with mucus, which forms a thick, continuous layer in the large intestine. However, in the small intestine, the mucus layer is thinner and discontinuous, allowing direct contact between epithelial cells and luminal bacteria. Also, under certain conditions, the mucus barrier is reduced, and bacteria can penetrate the layer and adhere to the underlying epithelial cells [37]. The canine jejunal isolate, LAB20, was previously found to persist in the gut of healthy dog for over six weeks after cessation of administration [24]. 
The long persistence in the canine GIT might be due to the effective adhesion to host IECs in the small intestine.

LAB20 was originally isolated from healthy canine jejunum, which makes it intriguing to it's potential immunomodulatory effects. Canine primary colonic epithelial cells isolated from normal dogs express TLR4 that can be stimulated in response to LPS [38]. On the other hand, increased expression of TLR4 has been linked to inflammatory bowel disease (IBD) in dogs [39-41]. Further, LPS-carrying Proteobacteria are increased in human IBD subjects [42], and this bacterial phylum and LPS may play a role also in canine IBD. In this study, we used LPS-induced inflammation in HT-29 cell line as a model, because HT-29 cells express TLR4 that mediates LPS stimulation in IECs [43]. We found that LAB20 is able to attenuate LPS-induced release of IL-8 from HT29 cell line. Previously, it has been shown that the stimulation of IECs with one MAMP can induce tolerance towards other MAMPs and modulate the inflammatory response of IECs [44]. This is a likely scenario also in the case of the attenuation of LPS-induced IL-8 secretion by LAB20. The result indicates that LAB20 could balance the IL-8 expression of enterocytes in response to apical stimulation by LPS from Gram-negative bacteria in the intestine. Most of the LPS-carrying bacteria in the GIT are harmless commensals. However, if the host responses to them are inappropriate or exaggerated, chronic inflammation (without infection) may ensue. There is growing evidence that aberrant innate immune responses towards the gut microbiota play a role in the pathogenesis of canine IBD [39,40]. Importantly, TLR4 expression is increased in dogs suffering from chronic enteropathies including IBD [39-41]. Thus, LAB20 seems to be able to induce in IECs tolerogenic response towards LPS derived from the intestinal microbiota.

Previously, bifidobacteria and Lactobacillus fermentum have been demonstrated to inhibit LPS or Yersinia enterocolitica -induced IL-8 production by IECs [45,46]. Moreover, several studies have shown that bifidobacteria and lactobacilli can reduce the severity of inflammation in vivo in rodent models and patients with IBD $[18,19,47]$. Our preliminary results suggest that EPS of LAB20 may have a role in the immunomodulatory activity of LAB20 (Additional file 1). Lactobacillus amylovorus inhibits the TLR4 inflammatory signaling triggered by enterotoxigenic $E$. coli and TLR2 is required for the suppression of TLR4 signaling activation [48]. Further, EPS of Lactobacillus delbrueckii have been shown to attenuate enterotoxigenic $E$. coli -induced inflammatory response in porcine IECs and TLR2 plays a central role in the immunomodulatory action [49]. Concerning LAB20, further studies are needed to confirm the antiinflammatory properties in vivo in dogs.
One of the proposed mechanisms of action of probiotic LAB is the ability to strengthen the epithelial barrier [50]. We measured Caco-2 cell monolayer's resistance, TER, as an indicator of GI-epithelial barrier function. Co-culture of Caco-2 cells with LAB20 fortified epithelial barrier, as demonstrated by the increase in TER. The Caco-2 cell line is a well-characterized model of the gut epithelium and is capable of differentiation and polarization [51] and measuring TER of polarized cell monolayers is commonly used as a screening assay to test for probiotic effects [45,52-54]. As expected, the non-pathogenic $E$. coli used in the experiment as a control disrupted the barrier integrity $[29,55]$. Thus, LAB20 can fortify intestinal barrier function by tightening the epithelial cell layer and inducing tolerance towards LPS.

\section{Conclusions}

In conclusion, we demonstrated that canine derived strain LAB20 has potential as a probiotic as it adheres to mucus and IECs and interact with the host. Specifically, it fortifies epithelial cell layer, and is able to elicit anti-inflammatory responses in enterocytes. The antiinflammatory property appeared to be associated with cell viability and activity, but the precise mechanisms, especially the components responsible for anti-inflammatory functions remain to be identified.

\section{Methods}

\section{Microorganisms and growth condition}

L. acidophilus LAB20 was previously isolated from canine jejunal chime [23]. It was cultured in LBS broth (BBL, Becton Dickinson) without acetic acid and $\mathrm{pH}$ adjusted to 7 with $5 \mathrm{M} \mathrm{NaOH}$ (mLBS7) to optimize LAB20 growth, and incubated at $37^{\circ} \mathrm{C}$ in anaerobic conditions. Freeze-dried LAB20 cells were prepared as described previously [24]. The viability of freeze-dried LAB20 is $8 \%$ after freeze-drying protocol and the recovery of freeze-dried LAB20 takes more than 8 hours. L. rhamnosus GG was cultured in MRS (Becton Dickinson) broth under static conditions at $37^{\circ} \mathrm{C}$ and E. coli TOP10 was cultured in Luria-Bertani broth (Becton Dickinson) at $37^{\circ} \mathrm{C}$.

\section{HT-29 cell and Caco- 2 cell cultures}

The human intestinal cell lines HT-29 and Caco-2 were obtained from DSMZ and were grown at $37^{\circ} \mathrm{C}$ in a $95 \%$ air-5\% $\mathrm{CO}_{2}$ atmosphere. HT-29 cells were grown in McCoy 5A medium (Lonza) supplemented with 10\% heat-inactivated $\left(56^{\circ} \mathrm{C}, 30 \mathrm{~min}\right)$ fetal calf serum (FCS, Integro B.V.) and $100 \mathrm{U} / \mathrm{ml}$ penicillin-streptomycin (Lonza). Caco-2 cells were grown in RPMI 1640 medium (Sigma-Aldrich) supplemented with $2 \mathrm{mM}_{\mathrm{L}}$-glutamine (Lonza), 20\% FCS, $100 \mathrm{U} / \mathrm{ml}$ penicillin-streptomycin, 15 
mM HEPES (Lonza), and 1\% nonessential amino acids (Lonza).

\section{Isolation of human and canine intestinal mucus}

Human colonic mucus was collected from a healthy piece of tissue obtained from patients with colorectal cancer, by following the previous description [56]. The use of resected human intestinal tissue for the adhesion studies was approved by the ethical committee of the Hospital District of Southwest Finland and the patients donating their samples for research purposes signed a written informed consent. Briefly, the mucus was collected into HEPES-Hanks buffer (10 mM HEPES, pH 7.4) by gently scraping with a rubber spatula from washed resected material (PBS containing $0.01 \%$ gelatin), and stored at $-20^{\circ} \mathrm{C}$ until use. Canine intestinal mucus was isolated from intestinal mucosa samples taken by necropsy from the duodenum, jejunum, ileum, cecum, and colon of six healthy dogs being euthanized after finalizing an unrelated experimental study. The study protocol was approved by the Finnish National Animal Experiment Board (License number ESAVI-2010-04178 Ym-23, PH 1465A). Fresh mucosa was isolated from the intestinal wall with the back side of a scalpel after thorough cleaning of the surface with cold saline. All samples were immediately frozen in liquid nitrogen and stored at $-80^{\circ} \mathrm{C}$ until being melted at room temperature for further processing. For the adhesion tests the samples were carefully centrifuged and the mucus and epithelial cells were separated.

\section{Bacterial adhesion to mucus and cell lines}

For the adhesion test, mucus samples (50 $\mu \mathrm{g}$ in PBS) were immobilized passively on Maxisorp microtiter wells by overnight incubation at $4^{\circ} \mathrm{C}$ [56]. The wells containing immobilized mucus were washed twice with PBS and incubated with blocking buffer $(0.5 \%$ [w/v] BSA in PBS) for one hour at room temperature. The Caco-2 and HT-29 cell lines were cultivated on 96-well tissue culture plate (10,000 cells/well; Nunc) for 3, 8 and 21 days. The cells were washed twice with culture medium before the adhesion assay. LAB20 was metabolically radiolabeled by cultivating bacteria with $10 \mu \mathrm{l} / \mathrm{ml}\left[5^{\prime}{ }^{3} \mathrm{H}\right]$ thymidine $(17.0 \mathrm{Ci} / \mathrm{mmol}$; Perkin Elmer). The adhesion assay was performed as described previously by Kainulainen et al. (2013) [57]. Briefly, after cultivation, bacteria were collected by centrifugation and washed with McCoy 5A (adhesion to HT-29) or RPMI (adhesion to Caco-2) without supplements, or PBS (adhesion to mucus). The optical density was adjusted $\left(\mathrm{OD} 600_{\mathrm{nm}}=\right.$ $0.25)$ to the same culture medium or buffer used for washing. Bacteria $(100 \mu \mathrm{l})$ were incubated on mucus at $37^{\circ} \mathrm{C}$ or on the IECs in a $\mathrm{CO}_{2}$ incubator at $37^{\circ} \mathrm{C}$ for one hour, and the non-adherent bacteria were removed by washing the wells three times with PBS. Bacteria bound to cells or mucus were lysed with $1 \%$ SDS- $-1 \mathrm{M} \mathrm{NaOH}$ by incubating at $60^{\circ} \mathrm{C}$ for one hour. The radioactivity of the suspension was measured by liquid scintillation. Four to five parallel wells (i.e. technical replicates) were used in each experiment, and all experiments were repeated two to four times. The percent bacterial adhesion was determined by calculating the ratio between the radioactivity of the adherent bacteria and that of the added bacteria.

\section{Bacterial adhesion to canine IECs}

Canine IECs were isolated from canine mucosa samples by separating the cells from mucus by centrifugation. The IECs from duodenum, jejunum, ileum, cecum, and colon were mounted on glass slides and fixed with $4 \%$ $(\mathrm{w} / \mathrm{v})$ paraformaldehyde (Sigma-Aldrich) in PBS (pH 7.4) for overnight at $4^{\circ} \mathrm{C}$. For the adhesion assay, a $1.5-\mathrm{ml}$ volume of LAB20 cells from two-night culture were collected by centrifugation and washed twice with PBS, then stained with $2.5 \mathrm{ml}$ of $75 \mu \mathrm{g} / \mathrm{ml}$ of fluorescein isothiocyanate (FITC; Sigma-Aldrich) in PBS (pH 8.2). After one hour incubation at room temperature in dark bacterial cells were washed with $0.01 \%$ Tween20-PBS ( $\mathrm{pH}$ 7.4), and the optical density was adjusted to $\mathrm{OD}_{600} \mathrm{~nm}=0.25$ with the same buffer used for washing. The FITC-labelled bacteria were incubated with canine IECs for one hour at room temperature in a moisture chamber to allow bacteria to bind. The slides were then washed in $50 \mathrm{ml}$ PBS for three times, and epithelial cells were stained with $10 \mu \mathrm{M}$ 4,6'-diamidino-2-phenylindole (DAPI; Molecular Probes), which binds to nucleic acids. The adherent bacteria were examined with an epifluorescence microscopy (Leica DM 4000B) and images were digitally recorded using CellP^ imaging software for life sciences microscopy (Soft Imaging System $\mathrm{GmbH}$ ). The assay was carried out twice with duplicate samples, and the figures are representative microscopic images of bacterial adherence.

\section{Induction of IL-8 release from HT-29 by LPS and the at- tenuation assay}

LAB20 cells were harvested from 36-40 hours culture by centrifugation and freeze-dried LAB20 cells were prepared as described previously [24]. Cells were washed once with McCoy 5A medium with FCS. The optical density of bacterial suspensions was adjusted to 0.25 at $600 \mathrm{~nm}$ (OD 600), respectively. A $100 \mu \mathrm{l}$ volume of each bacterial cell suspension was added to the wells containing 8-days-old HT-29 cells and incubated at $37^{\circ} \mathrm{C}$ for one hour in a $95 \%$ air $-5 \% \mathrm{CO}_{2}$ atmosphere. The control wells contained only McCoy 5A medium with FCS. Afterwards, the medium and bacterial suspension were removed from wells, and $200 \mu \mathrm{l}$ of $E$. coli LPS-containing $(0.1 \mathrm{ng} / \mathrm{ml}$ or $1 \mathrm{ng} / \mathrm{ml})$ medium were added. The HT-29 
cells were incubated with LPS for four hours, and the IL-8 concentration of the medium was measured by ELISA (Human IL-8 BD OptEIA ${ }^{\text {tw }}$ Kit, BD).

\section{Transepithelial electric resistance}

The effect of LAB20 on epithelial cell integrity was studied as previously described by Myllyluoma et al. [58] with minor modifications. Briefly, LAB20 and E. coli cells were harvested after cultivation by centrifugation and washed once with RPMI containing the supplements. The optical density was adjusted to $\mathrm{OD}_{600 \mathrm{~nm}}=$ 0.25 with the same RPMI medium. Caco-2 cells (50 000 cells/well) were cultured for eight days on cell culture inserts (Millipore) with a 3- $\mu \mathrm{m}$ pore size inserted in the wells of 24-well culture plate. The adjusted bacterial suspension $(400 \mu \mathrm{l})$ was added on the apical side of the insert and the cultures were incubated at $37^{\circ} \mathrm{C}$ under a $5 \%$ $\mathrm{CO}_{2}$ atmosphere for $72 \mathrm{~h}$. Transepithelial electrical resistance (TER) across the monolayers was measured by using Millicell ERS-2 TER meter (Millipore) at 24, 48 and $72 \mathrm{~h}$ of incubation. Measurements are expressed as $\Omega / \mathrm{cm}^{2}$ after subtracting the baseline mean resistance of the same inserts i.e. the resistance at time point 0 .

\section{Statistical analysis}

A pairwise Student's $t$ test was used to determine the significant difference $(P<0.05)$. Results are shown as means \pm standard deviations for technical replicates from representative experiments.

\section{Additional file}

Additional file 1: Construction of derivate strain SAA658 and comparison of WT-LAB20 and SAA658 in the IL-8 production assay.

\section{Competing interests}

The authors declare that they have no competing interests.

\section{Authors' contributions}

VK, YT, PJES and RS conceived and designed the study. VK, YT, JR designed and performed the experiments. TS and SK carried out the isolation of canine IECs and mucus samples. VK, YT and JR integrated the data. VK, YT and RS wrote the manuscript. All authors have been involved in revising the manuscript critically. All authors read and approved the final manuscript.

\section{Acknowledgements}

Professor Seppo Salminen from University of Turku, and M.D. Heikki Huhtinen from Turku University Central Hospital are thanked for providing the human intestinal samples. This study was funded by the Academy of Finland, project numbers 177321 and 138902, and the China Scholarship Council (CSC).

\section{Author details}

'Department of Veterinary Biosciences, Faculty of Veterinary Medicine, University of Helsinki, P.O. Box 66 (Agnes Sjöberginkatu 2)Fl-00014 Helsinki, Finland. ${ }^{2}$ Department of Food and Environmental Sciences, Faculty of Agriculture and Forestry, University of Helsinki, P.O. Box 56 (Viikinkaari 9) $\mathrm{Fl}-00014$ Helsinki, Finland. ${ }^{3}$ Department of Equine and Small Animal Medicine, Faculty of Veterinary Medicine, University of Helsinki, P.O. Box 57 (Viikintie 49)FI-00014 Helsinki, Finland.
Received: 25 August 2014 Accepted: 23 December 2014

Published online: 16 January 2015

\section{References}

1. Manichanh C, Borruel N, Casellas F, Guarner F. The gut microbiota in IBD. Nat Rev Gastroenterol Hepatol. 2012;9(10):599-608.

2. van Baarlen P, Wells JM, Kleerebezem M. Regulation of intestinal homeostasis and immunity with probiotic lactobacilli. Trends Immunol. 2013:34(5):208-15.

3. Tlaskalova-Hogenova H, Stepankova R, Kozakova H, Hudcovic T, Vannucci L, Tuckova $L$, et al. The role of gut microbiota (commensal bacteria) and the mucosal barrier in the pathogenesis of inflammatory and autoimmune diseases and cancer: contribution of germ-free and gnotobiotic animal models of human diseases. Cell Mol Immunol. 2011;8(2):110-20.

4. Bron PA, van Baarlen P, Kleerebezem M. Emerging molecular insights into the interaction between probiotics and the host intestinal mucosa. Nat Rev Microbiol. 2011;10(1):66-78.

5. de Kivit S, van Hoffen E, Korthagen N, Garssen J, Willemsen LE. Apical TLR ligation of intestinal epithelial cells drives a Th1-polarized regulatory or inflammatory type effector response in vitro. Immunobiology. 2011;216(4):518-27.

6. Gonzalez-Rodriguez I, Ruiz L, Gueimonde M, Margolles A, Sanchez B. Factors involved in the colonization and survival of bifidobacteria in the gastrointestinal tract. FEMS Microbiol Lett. 2013;340(1):1-10.

7. Kankainen M, Paulin L, Tynkkynen S, von Ossowski I, Reunanen J, Partanen P, et al. Comparative genomic analysis of Lactobacillus rhamnosus GG reveals pili containing a human- mucus binding protein. Proc Natl Acad Sci U S A. 2009:106(40):17193-8.

8. Sanchez B, Urdaci MC, Margolles A. Extracellular proteins secreted by probiotic bacteria as mediators of effects that promote mucosa-bacteria interactions. Microbiology. 2010;156(Pt 11):3232-42.

9. Kainulainen V, Korhonen TK. Dancing to another tune-adhesive moonlighting proteins in bacteria. Biology (Basel). 2014;3(1):178-204.

10. Walter J. Ecological role of lactobacilli in the gastrointestinal tract: implications for fundamental and biomedical research. Appl Environ Microbiol. 2008;74(16):4985-96

11. Sengupta R, Altermann E, Anderson RC, McNabb WC, Moughan PJ, Roy NC The role of cell surface architecture of lactobacilli in host-microbe interactions in the gastrointestinal tract. Mediators Inflamm. 2013:2013:237921.

12. Van Tassell ML, Miller MJ. Lactobacillus adhesion to mucus. Nutrients. 2011;3(5):613-36

13. Sanchez B, Bressollier P, Urdaci MC. Exported proteins in probiotic bacteria: adhesion to intestinal surfaces, host immunomodulation and molecular cross-talking with the host. FEMS Immunol Med Microbiol. 2008;54(1):1-17.

14. Collado MC, Jalonen L, Meriluoto J, Salminen S. Protection mechanism of probiotic combination against human pathogens: in vitro adhesion to human intestinal mucus. Asia Pac J Clin Nutr. 2006;15(4):570-5.

15. Selle K, Klaenhammer TR. Genomic and phenotypic evidence for probiotic influences of Lactobacillus gasseri on human health. FEMS Microbiol Rev. 2013:37(6):915-35.

16. Hakansson A, Molin G. Gut microbiota and inflammation. Nutrients. 2011;3(6):637-82

17. Mitsuyama K, Toyonaga A, Sasaki E, Watanabe K, Tateishi H, Nishiyama T, et al. IL-8 as an important chemoattractant for neutrophils in ulcerative colitis and Crohn's disease. Clin Exp Immunol. 1994;96(3):432-6.

18. Claes IJ, De Keersmaecker SC, Vanderleyden J, Lebeer S. Lessons from probiotic-host interaction studies in murine models of experimental colitis. Mol Nutr Food Res. 2011;55(10):1441-53.

19. Madsen K, Cornish A, Soper P, McKaigney C, Jijon H, Yachimec C, et al. Probiotic bacteria enhance murine and human intestinal epithelial barrier function. Gastroenterology. 2001;121(3):580-91.

20. Neuman MG, Nanau RM. Inflammatory bowel disease: role of diet, microbiota, life style. Transl Res. 2012;160(1):29-44.

21. O'Mahony L, McCarthy J, Kelly P, Hurley G, Luo F, Chen K, et al. Lactobacillus and Bifidobacterium in irritable bowel syndrome: symptom responses and relationship to cytokine profiles. Gastroenterology. 2005;128(3):541-51.

22. O'Mahony L, Feeney M, O'Halloran S, Murphy L, Kiely B, Fitzgibbon J, et al. Probiotic impact on microbial flora, inflammation and tumour development in IL-10 knockout mice. Aliment Pharmacol Ther. 2001;15(8):1219-25. 
23. Tang Y, Manninen TJ, Saris PE. Dominance of Lactobacillus acidophilus in the facultative jejunal Lactobacillus microbiota of fistulated beagles. Appl Environ Microbiol. 2012;78(19):7156-9.

24. Tang Y, Saris PE. Strain-specific detection of orally administered canine jejunum-dominated Lactobacillus acidophilus LAB20 in dog faeces by real-time PCR targeted to the novel surface layer protein. Lett Appl Microbiol. 2013;57(4):330-5

25. Joeres-Nguyen-Xuan TH, Boehm SK, Joeres L, Schulze J, Kruis W. Survival of the probiotic Escherichia coli Nissle 1917 (EcN) in the gastrointestinal tract given in combination with oral mesalamine to healthy volunteers. Inflamm Bowel Dis. 2010;16(2):256-62

26. Saxelin M, Lassig A, Karjalainen H, Tynkkynen S, Surakka A, Vapaatalo H, et al. Persistence of probiotic strains in the gastrointestinal tract when administered as capsules, yoghurt, or cheese. Int J Food Microbiol. 2010;144(2):293-300.

27. von Ossowski I, Satokari R, Reunanen J, Lebeer S, De Keersmaecker SC, Vanderleyden J, et al. Functional characterization of a mucus-specific LPXTG surface adhesin from probiotic Lactobacillus rhamnosus GG. Appl Environ Microbiol. 2011;77(13):4465-72.

28. Cruz N, Qi L, Alvarez X, Berg RD, Deitch EA. The Caco-2 cell monolayer system as an in vitro model for studying bacterial-enterocyte interactions and bacterial translocation. J Burn Care Rehabil. 1994;15(3):207-12

29. Cruz N, Alvarez X, Berg RD, Deitch EA. Bacterial translocation across enterocytes: results of a study of bacterial-enterocyte interactions utilizing Caco-2 cells. Shock. 1994;1(1):67-72.

30. Rastall RA. Bacteria in the gut: friends and foes and how to alter the balance. J Nutr. 2004;134(8 Suppl):2022S-6.

31. Sjogren YM, Jenmalm MC, Bottcher MF, Bjorksten B, Sverremark-Ekstrom E. Altered early infant gut microbiota in children developing allergy up to 5 years of age. Clin Exp Allergy. 2009;39(4):518-26.

32. Yan F, Polk DB. Commensal bacteria in the gut: learning who our friends are. Curr Opin Gastroenterol. 2004;20(6):565-71.

33. Rinkinen $M$, Westermarck $E$, Salminen $S$, Ouwehand AC. Absence of host specificity for in vitro adhesion of probiotic lactic acid bacteria to intestinal mucus. Vet Microbiol. 2003;97(1-2):55-61.

34. Velez MP, De Keersmaecker SC, Vanderleyden J. Adherence factors of Lactobacillus in the human gastrointestinal tract. FEMS Microbiol Lett. 2007;276(2):140-8.

35. Ganan M, Martinez-Rodriguez AJ, Carrascosa AV, Vesterlund S, Salminen S, Satokari R. Interaction of Campylobacter spp. and human probiotics in chicken intestinal mucus. Zoonoses Public Health. 2013:60(2):141-8.

36. Gagnon M, Zihler Berner A, Chervet N, Chassard C, Lacroix C. Comparison of the Caco-2, HT-29 and the mucus-secreting HT29-MTX intestinal cell models to investigate Salmonella adhesion and invasion. J Microbiol Methods. 2013;94(3):274-9.

37. Juge N. Microbial adhesins to gastrointestinal mucus. Trends Microbiol. 2012;20(1):30-9.

38. Swerdlow MP, Kennedy DR, Kennedy JS, Washabau RJ, Henthorn PS, Moore $P F$, et al. Expression and function of TLR2, TLR4, and Nod2 in primary canine colonic epithelial cells. Vet Immunol Immunopathol. 2006;114(3-4):313-9.

39. Allenspach K, House A, Smith K, McNeill FM, Hendricks A, Elson-Riggins J, et al. Evaluation of mucosal bacteria and histopathology, clinical disease activity and expression of Toll-like receptors in German shepherd dogs with chronic enteropathies. Vet Microbiol. 2010;146(3-4):326-35.

40. Burgener IA, König A, Allenspach K, Sauter SN, Boisclair J, Doherr MG, et al. Upregulation of toll-like receptors in chronic enteropathies in dogs. J Vet Intern Med. 2008;22(3):553-60.

41. McMahon LA, House AK, Catchpole B, Elson-Riggins J, Riddle A, Smith K, et al. Expression of Toll-like receptor 2 in duodenal biopsies from dogs with inflammatory bowel disease is associated with severity of disease. Vet Immunol Immunopathol. 2010;135(1-2):158-63.

42. Mukhopadhya I, Hansen R, El-Omar EM, Hold GL. IBD-what role do Proteobacteria play? Nat Rev Gastroenterol Hepatol. 2012;9(4):219-30.

43. Cario E, Rosenberg IM, Brandwein SL, Beck PL, Reinecker HC, Podolsky DK. Lipopolysaccharide activates distinct signaling pathways in intestinal epithelia cell lines expressing Toll-like receptors. J Immunol. 2000;164(2):966-72.

44. Abreu MT. Toll-like receptor signalling in the intestinal epithelium: how bacterial recognition shapes intestinal function. Nat Rev Immunol. 2010;10(2):131-44.

45. Preising J, Philippe D, Gleinser M, Wei H, Blum S, Eikmanns BJ, et al. Selection of bifidobacteria based on adhesion and anti-inflammatory capacity in vitro for amelioration of murine colitis. Appl Environ Microbiol. 2010;76(9):3048-51.
46. Frick JS, Schenk K, Quitadamo M, Kahl F, Koberle M, Bohn E, et al. Lactobacillus fermentum attenuates the proinflammatory effect of Yersinia enterocolitica on human epithelial cells. Inflamm Bowel Dis. 2007;13(1):83-90.

47. McCarthy J, O'Mahony L, O'Callaghan L, Sheil B, Vaughan EE, Fitzsimons N, et al. Double blind, placebo controlled trial of two probiotic strains in interleukin 10 knockout mice and mechanistic link with cytokine balance. Gut. 2003;52(7):975-80.

48. Finamore A, Roselli M, Imbinto A, Seeboth J, Oswald IP, Mengheri E. Lactobacillus amylovorus inhibits the TLR4 inflammatory signaling triggered by enterotoxigenic Escherichia coli via modulation of the negative regulators and involvement of TLR2 in intestinal Caco-2 cells and pig explants. PLoS One. 2014;9(4):e94891

49. Wachi Wachi S, Kanmani P, Tomosada Y, Kobayashi H, Yuri T, Egusa S, et al. Lactobacillus delbrueckii TUA4408L and its extracellular polysaccharides attenuate enterotoxigenic Escherichia coli-induced inflammatory response in porcine intestinal epitheliocytes via Toll-like receptor-2 and 4. Mol Nutr Food Res. 2014:58(10):2080-93.

50. Lebeer S, Vanderleyden J, De Keersmaecker SC. Genes and molecules of lactobacilli supporting probiotic action. Microbiol Mol Biol Rev. 2008;72(4):728-64. Table of Contents.

51. Hidalgo IJ, Raub TJ, Borchardt RT. Characterization of the human colon carcinoma cell line (Caco-2) as a model system for intestinal epithelial permeability. Gastroenterology. 1989;96(3):736-49.

52. Johnson-Henry KC, Donato KA, Shen-Tu G, Gordanpour M, Sherman PM. Lactobacillus rhamnosus strain GG prevents enterohemorrhagic Escherichia coli 0157:H7-induced changes in epithelial barrier function. Infect Immun. 2008;76(4):1340-8

53. Klingberg TD, Pedersen MH, Cencic A, Budde BB. Application of measurements of transepithelial electrical resistance of intestinal epithelial cell monolayers to evaluate probiotic activity. Appl Environ Microbiol. 2005;71(11):7528-30.

54. Otte JM, Podolsky DK. Functional modulation of enterocytes by gram-positive and gram-negative microorganisms. Am J Physiol Gastrointest Liver Physiol. 2004;286(4):G613-26.

55. Zareie M, Riff J, Donato K, McKay DM, Perdue MH, Soderholm JD, et al. Novel effects of the prototype translocating Escherichia coli, strain C25 on intestinal epithelial structure and barrier function. Cell Microbiol. 2005;7(12):1782-97.

56. Vesterlund S, Paltta J, Karp M, Ouwehand AC. Measurement of bacterial adhesion-in vitro evaluation of different methods. J Microbiol Methods. 2005:60(2):225-33

57. Kainulainen V, Reunanen J, Hiippala K, Guglielmetti S, Vesterlund S, Palva A. BopA does not have a major role in the adhesion of Bifidobacterium bifidum to intestinal epithelial cells, extracellular matrix proteins, and mucus. Appl Environ Microbiol. 2013;79(22):6989-97.

58. Myllyluoma E, Ahonen AM, Korpela R, Vapaatalo H, Kankuri E. Effects of multispecies probiotic combination on Helicobacter pylori infection in vitro. Clin Vaccine Immunol. 2008:15(9):1472-82.

\section{Submit your next manuscript to BioMed Central and take full advantage of:}

- Convenient online submission

- Thorough peer review

- No space constraints or color figure charges

- Immediate publication on acceptance

- Inclusion in PubMed, CAS, Scopus and Google Scholar

- Research which is freely available for redistribution 